\title{
EL RECURSO DE NULIDAD PENAL \\ ¿UN MECANISMO RESPETUOSO DEL DERECHO FUNDAMENTAL AL RECURSO?*
}

\author{
The appeal for criminal annulment
}

Is a respectful way of the fundamental right to the remedy?

\author{
RAOUF RADWAN ABOU-CHAKRA** \\ Universidad Católica de Temuco \\ JUAN PABLO BECA FREI *** \\ Universidad Católica de Temuco \\ LUIS IVÁN Díaz GARCíA**** \\ Universidad Católica de Temuco
}

\begin{abstract}
ReSUMEN
El presente realiza un estudio, por medio de revisión, de algunos aspectos del derecho procesal penal y derecho constitucional chileno, analizando el derecho al Recurso de Nulidad Penal, su origen; marco normativo; configuración y problemáticas asociadas a éste. A la vez, analiza, mediante revisión, algunos fallos de la Corte Interamericana de Derechos Humanos, parte de la doctrina nacional y latinoamericana sobre la materia, el rol del Control de Convencionalidad que deben ejercer los estados parte, intentando contribuir a determinar de qué manera nuestro país sigue, o debiese seguir, los lineamientos propuestos por la Corte Interamericana de Derechos Humanos sobre la materia y las normas recogidas en diversos instrumentos internacionales, a fin de verificar si cumple o no la actual configuración de nuestro recurso de nulidad penal el estándar internacional de garantizar el goce pleno y efectivo del derecho al recurso.
\end{abstract}

\section{PALABRAS CLAVE}

Control de Convencionalidad; derecho al recurso; recurso de nulidad penal.

\section{ABSTRACT}

This is a study, through review, of some aspects of criminal procedure law and Chilean constitutional law, analyzing the right to appeal for criminal annulment, its origin; regulatory framework; configuration and problems associated to it. At the same time, it analyzes, through the revision, some judgments of the InterAmerican Court of Human Rights, part of the national and Latin-American doctrine, the role of Conventionality Control that states parties must apply, trying to help to determine how our country follows, or should follow, the guidelines proposed by the Inter-American Court of Human Rights on the matter collected in different international instruments, in order to verify whether or not the current configuration of our criminal nullity appeal complies with the international standard of guaranteeing the full and effective enjoyment of the right to appeal.

\section{KEYWORDS}

Conventionality Control; right of appeal; appeal for criminal annulment.

\footnotetext{
*El presente trabajo es resultado de la tesis del autor principal en el programa de Magíster en Derecho, Mención Derecho Público, de la Universidad Católica de Temuco.

** Abogado Universidad Católica de Temuco, Chile; y Magister en Derecho, Mención Derecho Público, de la Universidad Católica de Temuco, Chile. Correo electrónico: raoufradwan@gmail.com.

${ }^{* * *}$ Académico de la Universidad Católica de Temuco, Chile. Abogado Universidad de Chile, Magíster en Derecho Universidad de Génova y Magíster en Derecho, Mención Derecho Constitucional, Universidad Católica de Temuco, Chile. Correo electrónico: jbeca@uct.cl.

${ }^{* * * *}$ Académico de la Universidad Católica de Temuco, Chile. Abogado Pontificia Universidad Católica de Chile. Doctor en Derecho Universidad Carlos III de Madrid, España. Correo electrónico: ivandiaz@uct.cl.
} 


\section{Introducción}

El Código Procesal Penal actualmente vigente en Chile fue incorporado al ordenamiento mediante la ley 19.696, del año 2000. Junto con la reforma constitucional de $1997^{1}$ y otras leyes ${ }^{2}$, permitió sustituir el sistema inquisitivo vigente por un modelo acusatorio formal. Con este Código se pretendió establecer un proceso penal respetuoso de los derechos humanos, en general, y del derecho fundamental al debido proceso, en particular ${ }^{3}$.

Nadie podría poner en duda el enorme avance que significó la nueva justicia penal desde el punto de vista del respeto a los derechos humanos. Tampoco es posible negar que el Código Procesal Penal se ajusta mucho más que el antiguo Código de Procedimiento Penal al debido proceso. Todo aquello no significa, sin embargo, que la regulación vigente deba quedar exenta de evaluaciones. Toda norma del ordenamiento, y también el Código mencionado, puede y debe ser permanentemente evaluada desde los derechos fundamentales.

Evidentemente, diversos son los aspectos que podrían ser objeto de la evaluación que se comenta. Uno de ellos será objeto del presente estudio: el diseño del recurso de nulidad penal. En particular, interesa analizar si ese diseño, y sus consecuencias, por cierto, es respetuoso de las exigencias establecidas por el derecho fundamental a un recurso procesal para impugnar la sentencia.

Desde tales coordenadas, la pregunta que guía la presente investigación puede ser planteada de la siguiente manera: ¿̇el recurso de nulidad penal, tanto en su diseño normativo como en las consecuencias jurídicas que derivan de dicho diseño, es respetuoso de las exigencias establecidas por el derecho fundamental a un recurso procesal para impugnar la sentencia?

La hipótesis de este trabajo responde negativamente aquella cuestión. Sostenemos que el recurso de nulidad penal no es respetuoso del derecho fundamental a un recurso procesal para impugnar la sentencia. No lo es desde el punto de vista del diseño que se le ha dado en el Código Procesal Penal. Tampoco desde el punto de vista de las consecuencias jurídicas que se desprenden de dicha regulación.

Con la finalidad de responder la pregunta planteada y confirmar o refutar la hipótesis, la exposición se organiza en torno a tres apartados. En el primero de ellos se presenta el estándar conforme al cual será evaluado el objeto. Esto se traduce en recordar el contenido (que incluye las exigencias) del derecho fundamental a un recurso procesal para impugnar la sentencia. En el segundo apartado se presenta el objeto a evaluar. Corresponde, por tanto, a la descripción de la regulación normativa del recurso de nulidad penal y las consecuencias jurídicas de dicho diseño. En el tercero se realiza el análisis de comparación entre el estándar y el objeto. Aquello se traduce en evaluar si el recurso de nulidad penal satisface las exigencias del derecho fundamental en cuestión.

\section{Exigencias del derecho fundamental a un recurso}

El presente apartado describe el estándar al que será sometido el objeto de estudio. Para este efecto, se divide en tres partes. En la primera de ellas se justifica el carácter iusfundamental del derecho al recurso en sede penal. Tal justificación es imprescindible, porque es precisamente dicho carácter lo que lo transforma en estándar de evaluación. En la segunda se explicitan las exigencias del derecho al recurso para impugnar la sentencia penal. El conjunto de tales exigencias constituye el estándar de evaluación que será utilizado en este texto. Luego, en la tercera, se aborda el Control de Convencionalidad como mecanismo de integración de la normativa internacional sobre el derecho al recurso a nuestro ordenamiento jurídico.

\footnotetext{
${ }^{1}$ Ley 19.519, de 1997.

${ }^{2}$ Ley 19.640, de 1999; Ley 19.718, de 2001.

${ }^{3}$ Así lo expresó Su excelencia el Presidente de la República de Chile en el mensaje del año 1995 en que envió el proyecto de Código Procesal Penal actualmente vigente al Congreso Nacional. Ver BIBLIOTECA DEL CONGRESO NACIONAL (2018), p. 3.
} 


\subsection{Carácter iusfundamental del derecho a un recurso}

Los tratados internacionales sobre derechos humanos incluyen normas que consagran lo que se conoce como "debido proceso", especialmente en sede penal. Así ocurre en la Declaración Americana de Derechos y Deberes del Hombre de $1948^{4}$, en el artículo 14 del Pacto Internacional de Derechos Civiles y Políticos, en adelante el Pacto, y en el artículo 8 de la Convención Americana sobre Derechos Humanos, en adelante CADH o Convención Americana. La Corte Interamericana de Derechos Humanos, en adelante Corte IDH, afirma que esta última disposición expresa "el conjunto de requisitos que deben observarse en las instancias procesales para que pueda hablarse de verdaderas y propias garantías judiciales según la Convención" 5 .

En nuestro país, la expresión debido proceso recibe la denominación de justo y racional procedimiento. Lo anterior, tiene su origen en la sesión número 83 de la Comisión de Estudio de la Nueva Constitución, en la cual se buscó apartarse de la expresión debido proceso por ser término inglés inserto en del derecho anglosajón ${ }^{6}$ que podría traer problemas prácticos e interpretativos en nuestro modelo que difiere del régimen jurídico anglosajón, ya que podría llevar a confusiones en la recta interpretación del sistema jurídico que la comisión deseó incorporar ${ }^{7}$. Es así, como la Constitución chilena asegura algunas garantías judiciales mínimas bajo la denominación de "la igual protección de la ley en el ejercicio de sus derechos" ${ }^{8}$. Sin embargo, no reconoce expresamente este derecho al debido proceso ${ }^{9}$.

Uno de los derechos incluidos en el debido proceso es el derecho fundamental a un recurso. El Pacto en su artículo 14.5 asegura este derecho en los siguientes términos: "Toda persona declarada culpable de un delito tendrá derecho a que el fallo condenatorio y la pena que se le haya impuesto sean sometidos a un tribunal superior, conforme a lo prescrito por la ley". La Convención Americana, por su parte, contempla el mismo derecho en su artículo 8.2 letra h, al conferir el "derecho de recurrir del fallo ante juez o tribunal superior".

La Constitución chilena no incluye expresamente el derecho al recurso ${ }^{10}$. Su regulación parece haber sido encomendada al legislador, como mandata la parte final del inciso sexto del artículo 19 número $3^{11}$. Sin embargo, el Tribunal Constitucional se encargó de corregir esa deficiencia, otorgando jerarquía constitucional al derecho en referencia, mediante la adscripción de normas a las directamente establecidas en el texto constitucional ${ }^{12}$. En efecto, en diversas sentencias ha sostenido que el derecho al racional y justo procedimiento, contemplado en la Constitución, incluye el derecho a un recurso para impugnar la sentencia ${ }^{13}$. Y, en el ámbito penal, ha precisado lo siguiente: "Tratándose del imputado criminal, dicho derecho es expresamente reconocido en tratados internacionales ratificados por Chile y que se encuentran vigentes" ${ }^{14}$.

\footnotetext{
${ }^{4}$ Declaración Americana de Derechos y Deberes del Hombre, de 1984, artículo 26.

${ }^{5}$ CORTE INTERAMERICANA DE DERECHOS HUMANOS (2017), p. 4

${ }^{6}$ BIBLIOTECA DEL CONGRESO NACIONAL (1974). Opinión del profesor Evans en Sesión № 83, Segunda Parte, de fecha 31 de octubre de 1974 de la Comisión de Estudios de la Nueva Constitución p. 516.

${ }^{7}$ BIBLIOTECA DEL CONGRESO NACIONAL (1974). Opinión del profesor Silva Bascuñán en Sesión № 83, Segunda Parte, de fecha 31 de octubre de 1974 de La Comisión de Estudios de la Nueva Constitución p. 517.

${ }^{8}$ Constitución Política de la República de Chile, Artículo 19 número 3.

${ }^{9}$ GARCÍA Y CONTRERAS (2013), p. 235.

${ }^{10}$ Sin perjuicio de ello, en la actualidad existe un proyecto de ley de reforma constitucional, el cual tiene su origen en una moción parlamentaria presentada por un grupo de Diputados la cual, a la fecha, se encuentra en segundo trámite constitucional ante el Senado. Con ésta se pretende, entre otras medidas, reformular la actual construcción del artículo 19 número 3 de nuestra carta fundamental incluyendo expresamente un listado de otros derechos, ordenados por letras, dentro de los cuales se encuentra el derecho al recurso en la letra $m$ de dicha propuesta. Ver CÁMARA DE DIPUTADOS (2017), p. 21.

${ }^{11}$ Artículo 19, número 3, inciso sexto de la Constitución Política de la República de Chile. "Corresponderá al legislador establecer siempre las garantías de un procedimiento y una investigación racionales y justos."

${ }^{12}$ ALEXY (2001), pp. 62-80.

${ }^{13}$ Por todas, puede citarse la sentencia Tribunal Constitucional, Rol № 3119-2016, de 20 de abril de 2017, cuyo considerando décimo noveno expresa que "Que, tal como lo ha expresado esta Magistratura en sentencias anteriores, la Constitución Política de la República asegura a todas las personas el derecho a un proceso previo, legalmente tramitado, racional y justo, el cual [incluye] la facultad de interponer recursos para revisar las sentencias dictadas por tribunales inferiores".

${ }^{14}$ Tribunal Constitucional, Rol № 1443-2010, de 26 de agosto de 2010, considerando duodécimo; Tribunal Constitucional, Rol № 31192016, de 20 de abril de 2017.
} 
La doctrina nacional coincide en atribuir carácter de derecho fundamental al derecho al recurso. En este sentido, Del Río afirma que "la existencia de un derecho al recurso aparecería naturalmente exigido por el justo proceso en cuanto medio procesal-epistémico dispuesto en el proceso para la obtención de decisiones correctas o justas" ${ }^{15}$. García y Contreras coinciden en adscribir el derecho al recurso en el derecho al proceso debido ${ }^{16}$. Bordalí, por su parte, coincide en este carácter iusfundamental, aunque lo incluye en el derecho a la tutela judicial efectiva ${ }^{17}$.

De este modo, el derecho a un recurso procesal para impugnar la sentencia es un derecho fundamental en el ordenamiento jurídico chileno. Así lo establecen tanto el Derecho internacional al que Chile se encuentra jurídicamente obligado, como las normas constitucionales de precisión de fuente jurisprudencial y la doctrina chilena.

\subsection{Exigencias del derecho a un recurso}

\subsubsection{El imputado debe tener derecho a un recurso}

La Corte Interamericana de Derechos Humanos ha establecido que "el derecho de recurrir del fallo es una garantía primordial que se debe respetar en el marco del debido proceso legal, en aras de permitir que una sentencia adversa pueda ser revisada por un juez o tribunal distinto y de superior jerarquía orgánica"18.

Complementando esta idea, ha sostenido que "la Corte interpreta que el derecho a recurrir el fallo no podría ser efectivo si no se garantiza respecto de todo aquél que es condenado, ya que la condena es la manifestación del ejercicio del poder punitivo del Estado". El derecho al recurso incluso se debe garantizar "frente a quien es condenado mediante una sentencia que revoca una decisión absolutoria", sostiene la Corte Interamericana ${ }^{19}$.

\subsubsection{Debe tratarse de un recurso ordinario, eficaz y sencillo}

La Corte IDH en el emblemático caso Mohamed vs. Argentina sostuvo que el artículo 8.2.h de la Convención se refiere a un recurso ordinario, eficaz y accesible (es decir, sencillo). Que sea ordinario, precisó, supone que debe ser garantizado antes de que la sentencia adquiera la calidad de cosa juzgada ${ }^{20}$.

La Corte explica que la eficacia del recurso implica que debe procurar resultados o respuestas al fin para el cual fue concebido ${ }^{21}$. Complementando esta idea, ha sostenido que debe tratarse de un recurso "mediante el cual un juez o tribunal superior procure la corrección de decisiones jurisdiccionales contrarias al derecho" y que "no puede reducirse a una mera formalidad, sino que debe examinar las razones invocadas por el demandante y manifestarse expresamente sobre ellas" 22 . En palabras de Letelier, "la eficacia del recurso opera como baremo para verificar su potencia como herramienta de impugnación" ${ }^{23}$.

\footnotetext{
${ }^{15}$ DEL RÍO (2010), p. 134.

${ }^{16}$ GARCÍA Y CONTRERAS (2013), p. 239.

${ }^{17}$ BORDALÍ (2011), p. 333.

${ }^{18}$ Herrera Ulloa vs. Costa Rica (2004), Corte Interamericana de Derechos Humanos. Párrafo 158. Exactamente el mismo texto se encuentra en Norín Catrimán y otros vs. Chile (2014), Corte Interamericana de Derechos Humanos. Párrafo 269, Amrhein y otros vs. Costa Rica (2018), Corte Interamericana de Derechos Humanos, Párrafo 255, y Ruiz Fuentes y otra vs. Guatemala (2019), Corte Interamericana de Derechos Humanos, Párrafo 157.

${ }^{19}$ Norín Catrimán y otros vs. Chile (2014), Corte Interamericana de Derechos Humanos. Párrafo 270, letra e), y Amrhein y Otros vs. Costa Rica (2018), Corte Interamericana de Derechos Humanos. Párrafo 255.

${ }^{20}$ Mohamed vs. Argentina (2012), Corte Interamericana de Derechos Humanos. Párrafo 99, Norín Catrimán y otros vs. Chile (2014), Corte Interamericana de Derechos Humanos. Párrafo 270, letra a), y Ruiz Fuentes y otra vs. Guatemala (2019), Corte Interamericana de Derechos Humanos, Párrafo 157.

${ }^{21}$ Amrhein y Otros vs. Costa Rica (2018), Corte Interamericana de Derechos Humanos. Párrafo 257. En el mismo sentido, Herrera Ulloa vs. Costa Rica (2004), Corte Interamericana de Derechos Humanos. Párrafo 161, y Mohamed vs. Argentina (2012), Corte Interamericana de Derechos Humanos. Párrafo 99.

${ }_{22}$ Mohamed vs. Argentina (2012), Corte Interamericana de Derechos Humanos. Párrafo 121, Norín Catrimán y otros vs. Chile (2014), Corte Interamericana de Derechos Humanos. Párrafo 270, letra c), y Amrhein y Otros vs. Costa Rica (2018), Corte Interamericana de Derechos Humanos. Párrafo 267.

${ }^{23}$ LETELIER (2014), p. 146.
} 
Recogiendo lo dictaminado por el Comité de Derechos Humanos de Naciones Unidas, la Corte alude a la exigencia de sencillez. Al respecto afirma que "la posibilidad de 'recurrir el fallo' debe ser accesible, sin requerir mayores complejidades que tornen ilusorio este derecho". Explicando esta idea, ha agregado que: "En ese sentido, las formalidades requeridas para que el recurso sea admitido deben ser mínimas y no deben constituir un obstáculo para que el recurso cumpla con su fin de examinar y resolver los agravios sustentados por el recurrente" ${ }^{24}$.

\subsubsection{El recurso debe permitir una revisión integral del fallo impugnado}

El Comité de Derechos Humanos de Naciones Unidas señala que el derecho al recurso se garantiza con permitir una revisión integral del fallo impugnado, de modo que haga posible una revisión total del fondo ${ }^{25}$. No precisa, sin embargo, la forma en que deba configurarse dicho recurso, es decir, si bajo la lógica de un recurso que permite conocer los hechos y el Derecho (como la apelación) o como un recurso que solo permita conocer el Derecho (como el de nulidad).

En el mismo sentido, la Corte IDH ha sostenido que debe hacerse una revisión íntegra del fallo. Sin embargo, ha ido más allá al sostener que se debe contemplar la posibilidad de revisar tanto los hechos como el derecho. Siguiendo esta ilación, sostuvo que: "El Tribunal reitera que las causales de procedencia del recurso asegurado por el artículo 8.2.h) de la Convención deben posibilitar que se impugnen cuestiones con incidencia en el aspecto fáctico del fallo condenatorio ya que el recurso debe permitir un control amplio de los aspectos impugnados, lo que requiere que se pueda analizar cuestiones fácticas, probatorias y jurídicas en las que está fundada la sentencia condenatoria" ${ }^{26}$. Esto se debe, como explica la misma Corte, a que "en la actividad jurisdiccional existe una interdependencia entre las determinaciones fácticas y la aplicación del derecho, de forma tal que una errónea determinación de los hechos implica una errada o indebida aplicación del derecho" ${ }^{27}$.

En idéntica dirección, parte de nuestra doctrina entiende que el alcance de la revisión no sólo debe limitarse a constatar si hubo o no vicios. Al respecto Palomo y Alarcón sostienen que "el derecho al recurso ante el tribunal superior debe ser una reconsideración de tendencia general de las cuestiones de hecho y de derecho (meritum causae) y no sólo una querella nullitatis" 28 . En el mismo sentido, Nogueira afirma que el derecho al recurso exige que "la sentencia en materia penal sea revisada integralmente por otro tribunal superior, tanto en sus aspectos de hecho como de derecho" ${ }^{29}$.

\subsection{El derecho al recurso en nuestro ordenamiento jurídico y el Control de Convencionalidad}

Como se advirtió, el derecho al recurso no se encuentra definido ni regulado como tal en nuestra carta fundamental. Sin embargo, la reforma constitucional del año 1989, al incorporar el inciso segundo al artículo 5o, favorece la aplicación de los artículos 14.5 del Pacto Internacional de Derechos Civiles y Políticos y 8.2 letra h) de la Convención Americana sobre

\footnotetext{
${ }^{24}$ Amrhein y Otros vs. Costa Rica (2018), Corte Interamericana de Derechos Humanos. Párrafo 257, Norín Catrimán y otros vs. Chile (2014), Corte Interamericana de Derechos Humanos. Párrafo 270, letra b), y Ruiz Fuentes y otra vs. Guatemala (2019), Corte Interamericana de Derechos Humanos, Párrafo 158. En igual sentido, Herrera Ulloa vs. Costa Rica (2004), Corte Interamericana de Derechos Humanos. Párrafo 164. Fallo que estableció responsabilidad internacional del Estado de Costa Rica a raíz de la condena por difamación en contra de Mauricio Herrera Ulloa y la falta de la configuración de un recurso adecuado para que este último pueda impugnar tal medida. En el mismo sentido, ver sentencia de la Corte recaída en el caso Mohamed vs. Argentina (2012), Corte Interamericana de Derechos Humanos. Párrafo 99.

${ }^{25}$ COMITÉ DE DERECHOS HUMANOS DE NACIONES UNIDAS (2000).

${ }^{26}$ Norín Catrimán y Otros vs. Chile (2014), Corte Interamericana de Derechos Humanos. Párrafos 268 y 270 , letra d). En el mismo sentido, Amrhein y Otros vs. Costa Rica, Corte Interamericana de Derechos Humanos. Párrafo 256.

${ }^{27}$ Ruiz Fuentes y otra vs. Guatemala (2019), Corte Interamericana de Derechos Humanos, Párrafo 158.

28 PALOMO Y ALARCÓN (2011), p. 313.

${ }^{29}$ NOGUEIRA (2008), p. 368.
} 
Derechos Humanos en lo atingente al derecho al recurso ${ }^{30}$. La fuerza vinculante de estos instrumentos internacionales tiene su fuente en el artículo 27 de la Convención de Viena sobre el derecho de los tratados ${ }^{31}$, la cual consagra que un Estado parte no podrá invocar disposiciones de su Derecho interno como justificación para el incumplimiento de un tratado internacional, ratificado y vigente.

Sin perjuicio de lo anterior, y a modo de colaborar con la aplicación armónica de los derechos humanos sobre la materia en la normativa interna, y en el intento de evitar lesiones a estos derechos por parte de los estados, principalmente por vía judicial, la Corte IDH invita en el año $2006^{32}$ a los estados parte a realizar el denominado Control de Convencionalidad, el cual tiene su génesis en el año $2003^{33}$, a raíz del voto razonado por uno de sus jueces ${ }^{34}$ en el fallo del caso Myrna Mack Chang con Guatemala"35, el cual fue concebido "como una herramienta jurídica, dinámica, adecuada, útil y fundamental que surge de las convenciones o tratados internacionales sobre derechos humanos como primera fuente de juridicidad y busca lograr el cumplimiento y debida implementación de la sentencia internacional" ${ }^{\prime 3}$.

En la práctica, es una comparación entre el derecho local, tanto de la carta fundamental como de las demás normas, y el supranacional, ejercido en primer lugar por los estados y, eventualmente, por la Corte IDH en caso de promoverse un asunto que llegue a su sometimiento ${ }^{37}$, en palabras de Henríquez "se trata de un control de compatibilidad, consistencia, conformidad de las normas internas en relación con la Convención Americana y la interpretación que la Corte ha hecho de esta última" ${ }^{38}$.

De este modo, ejerciendo el denominado Control de Convencionalidad se "viene a concretar la obligación de garantía, mediante un ejercicio hermenéutico que consiste en la verificación que realiza la Corte IDH y todos los agentes estatales, de la adecuación de las normas jurídicas internas a la Convención Americana sobre Derechos y a los estándares interpretativos desarrollados en la jurisprudencia de dicho tribunal, aplicando en cada caso concreto aquella interpretación que se ajuste a las obligaciones internacionales del Estado y que dé efectividad a los derechos consagrados convencionalmente" ${ }^{39}$.

Así, en principio, se forja la idea de que sean los propios estados, a través de sus tribunales de justicia, para efectos del presente, quienes de forma autónoma tengan en consideración y apliquen los estándares internacionales sobre derechos humanos al momento de pronunciarse sobre un asunto sometido a su conocimiento en caso que el legislador no cumpla su obligación de adecuación, ya que "cuando el legislador no cumple con este mandato, es deber de los jueces domésticos ejercer el control de convencionalidad" ${ }^{40}$. De esta última afirmación se vislumbra que la Corte IDH ya no habla de una especie de control, sino que, derechamente, y conforme el avance jurisprudencial, lo sienta como una obligación para los estados especificando quienes son los destinatarios de este mandato.

Entendiéndolo así, el Control de Convencionalidad exigido por la Corte IDH podría salvar algunos problemas del derecho interno y vulneración de derechos, ya que "puede ser un camino

\footnotetext{
${ }^{30}$ DEL RÍO (2012), p. 255.

${ }^{31}$ Convención de Viena sobre el derecho de los tratados, artículo 27: "El derecho interno y la observancia de los tratados. Una parte no podrá invocar las disposiciones de su derecho interno como justificación del incumplimiento de un tratado. Esta norma se entenderá sin perjuicio de lo dispuesto en el artículo 46."

${ }^{32}$ Almonacid Arellano y otros con Chile (2006), Corte Interamericana de Derechos Humanos. Párrafo 124.

${ }^{33}$ Así lo ha entendido gran parte de la doctrina sudamericana, dejando en claro que en el año 2003 se esbozan las primeras ideas de este concepto, siendo la primera invitación a los demás estados para aplicarlo (HENRÍQUEZ (2018), p. 339; HITTERS (2009), p. 113; HITTERS (2015), p. 153; NASH (2013), p. 495; OLANO (2016), p. 63).

${ }^{34}$ Voto concurrente razonado por el Juez Sergio García Ramírez de la Corte IDH.

${ }_{35}$ Myrna Mack Chang con Guatemala (2003), Corte Interamericana de Derechos Humanos. En época de conflicto interno vivido en Guatemala, Myrna Mack Chang investigó los abusos cometidos por el ejército guatemalteco en ese contexto. Fue vigilada y asesinada por militares. La Corte IDH falló y declaró que dicho Estado violó el derecho a la vida, consagrado en el artículo 4.1; los derechos a las garantías judiciales de los artículos $8^{\circ}$ y 25 y; a la integridad personal, artículo 5.1, todos de la CADH.

${ }^{36}$ OLANO (2016), p. 63.

${ }^{37}$ HITTERS (2009), p. 113.

${ }^{38}$ HENRÍQUEZ (2019), p. 136.

${ }^{39} \mathrm{NASH}$ (2013), p. 492.

40 HENRÍQUEZ (2018), p. 340.
} 
para asegurar una aplicación armónica del derecho vigente, considerando tanto sus fuentes internas, internacionales como así también las supranacionales" ${ }^{\prime 11}$ ante las deficiencias de la normativa nacional, a fin de garantizar el pleno y efectivo disfrute de los derechos.

Un ejemplo paradigmático del carácter vinculante de las decisiones de la Corte Interamericana se encuentra en la sentencia AD 1386-2014, de la Corte Suprema, de fecha 16 de mayo de 2019. En la oportunidad sostuvo textualmente que "la sentencia de la Corte que motiva este pronunciamiento se hace obligatoria para el Estado de Chile, y la inexistencia de mecanismos, constitucionales o legales, que prevean los pasos a seguir para darle íntegro cumplimiento, impone a este Poder del Estado el deber de identificar las vías a través de las cuales satisfacer lo ordenado por ese tribunal" ${ }^{42}$. Y lo solicitado por la Corte en el caso fue dejar sin efecto en todos sus extremos las sentencias internas que se determinaron como violatorias de la Convención. Esas sentencias recayeron en el caso que ante la Corte Interamericana se denominó Norín Catrimán y otros vs. Chile. Por lo mismo, la Corte Suprema declaró que los fallos condenatorios, dictados en las causas internas impugnadas en el caso mencionado, han perdido los efectos que les son propios.

Sin embargo, es dable señalar que lo anterior no resuelve lo que parte de nuestra doctrina han advertido, por cuanto lo realizado por nuestro máximo tribunal es acatar una sentencia condenatoria contra el estado chileno, no efectuar una interpretación armónica de la normativa supra nacional con la interna o control normativo de alguna especie ${ }^{43}$.

No obstante lo anterior, parte de nuestra doctrina cuestiona la viabilidad de esta herramienta, de origen jurisprudencial, en aquellos estados que no cuenten con el valor vinculante del precedente ${ }^{44}$. Otros, en cambio, critican que no exista un criterio aunado que emane por parte de nuestros tribunales superiores de justicia con reglas o principios que sirvan de lineamiento a los tribunales inferiores en virtud de la calidad argumentativa de los primeros ${ }^{45}$ $y$, de este modo, si el juez del tribunal inferior decidiera fallar de forma distinta será éste quien deba sostener, en primer lugar, el criterio del tribunal superior $y$, en segundo término, las motivaciones por las cuales no lo ha seguido ${ }^{46}$.

Lo expuesto arroja un problema práctico en el asentamiento del derecho al recurso en nuestro ordenamiento jurídico, puesto que lo señalado por la Corte IDH, respecto del Control de Convencionalidad, pasa a ser vinculante para los tribunales de derecho interno, quienes deben cumplir este mandato que busca la integración de normas al derecho interno así como la expulsión ${ }^{47}$ de aquellas que no guarden respeto con la CADH y con los fallos de la Corte IDH como intérprete final de la Convención Americana ${ }^{48}$. El ejercicio de este control de convencionalidad por parte de los tribunales nacionales permite, además, evitar que el Estado incurra en responsabilidad internacional, por no aplicar la Convención Americana. Sin embargo, este mandato y la expectativa se divorciarían de la realidad, ya que, como se advierte, ello quedará al criterio de cada tribunal pudiendo existir razonamientos disímiles.

\section{Regulación del recurso de nulidad penal}

En el presente apartado se expone el objeto a evaluar y se divide en dos partes. La primera de ellas tiene un carácter introductorio. En ella se exponen, concisamente, los antecedentes relativos al origen del recurso de nulidad penal. La segunda parte describe el objeto mismo.

\footnotetext{
${ }^{41}$ BECA (2014), p. 491.

${ }^{42}$ Corte Suprema de Justicia de Chile, Rol AD-1386-2014, de 16 de mayo de 2019.

43 HENRÍQUEZ (2019), p. 148.

${ }^{44}$ GALDÁMEZ (2014), p. 355; HENRÍQUEZ (2018), p. 340.

${ }^{45}$ BORDALÍ (2013), p. 629.

${ }^{46}$ BORDALÍ (2013), p. 630.

${ }^{47}$ NASH (2013), p. 504. En relación a este tema, el autor identifica como una dificultad en la aplicación del Control de Convencionalidad la idea de pensar en la expulsión efectiva de normas internas contrarias a la $\mathrm{CADH}, \mathrm{y}$ la aclara indicando que el Control debe desarrollarse en el marco de las facultades y posibilidades internas de cada país.

${ }^{48}$ Almonacid Arellano y otros con Chile (2006), Corte Interamericana de Derechos Humanos. Párrafo 124.
} 
Dicha descripción se realiza mediante una breve exposición de las características más relevantes del recurso en análisis.

\subsection{Antecedentes del recurso de nulidad penal}

El derecho al recurso para impugnar la sentencia no aparece explícitamente contemplado en el Código Procesal Penal (en adelante también CPP). Sin embargo, resulta posible desprenderlo de una serie de normas incluidas en el mismo. En efecto, el artículo 4ㅇ del CPP establece que nadie será tratado como culpable en tanto no fuere condenado por sentencia firme. Por su parte, el artículo 7ํ del mismo código prescribe que los derechos y garantías que la constitución reconoce al imputado podrán hacerse valer a quien se le atribuye participación desde la primera actuación en su contra y hasta la ejecución de la sentencia. Siguiendo esta línea, el artículo 10 del código del ramo reconoce de forma directa las garantías judiciales consagradas en los tratados internacionales ratificados por Chile y vigentes ${ }^{49}$. Finalmente, el artículo 352 del CPP permite recurrir a cualquier interviniente agraviado. La sistemática de las normas mencionadas permite afirmar que el derecho a un recurso para impugnar la sentencia se encuentra contemplado en el Código Procesal Penal.

Ese derecho al recurso se materializa a través del recurso de nulidad penal, el cual fue introducido por la reforma Procesal Penal del año 2000, la que transformó el sistema procesal penal de nuestro país vigente hasta ese entonces ajustándose a estándares internacionales, pasando de un modelo inquisitivo hacia uno acusatorio ${ }^{50}$, en el cual "al imputado se le reconoce su calidad de sujeto de derecho al que le corresponden una serie de garantías penales de carácter sustantivo y procesal, integrantes de las exigencias del debido proceso, que constituyen límites infranqueables para el poder penal del Estado" 51 .

De este modo, el recurso de nulidad se forja como una herramienta especializada en contra de la sentencia definitiva pronunciada con ocasión de un juicio oral, apartándose el proceso penal del sistema recursivo procesal civil vigente hasta el inicio de la nueva justicia penal. Esta opción no estuvo, por cierto, exenta de controversias.

Efectivamente, durante la discusión legislativa se mencionaron los problemas que podría producir el desechar el recurso de apelación en contra de la sentencia definitiva dictada en un juicio oral. Al efecto se sostuvo que este nuevo recurso resulta mucho más estricto y riguroso en su configuración, lo que podría atentar contra el derecho al recurso. Por lo demás, no permite revisar los hechos del caso ${ }^{52}$. Para enfrentar esas objeciones, durante la discusión parlamentaria en el Senado se propuso incorporar un "recurso extraordinario". Este mecanismo permitiría impugnar ante la Corte de Apelaciones aquella sentencia condenatoria pronunciada en un juicio oral que se apartara manifiesta y arbitrariamente de la prueba rendida ${ }^{53}$. De este modo, se podría, en forma indirecta, discutir los hechos y con ello darle un mayor rol a los tribunales superiores.

Sin embargo, la idea de un recurso extraordinario no prosperó. Para desecharlo se sostuvo que, si se permitía discutir nuevamente los hechos, se restaba valor a la apreciación directa de la prueba que se verificaba durante el juicio oral, con lo que se le podría restar valor al eje de la reforma. Por otra parte, aquella contradecía la norma que permitía a los jueces del tribunal oral en lo penal apreciar libremente la prueba.

\footnotetext{
49 DEL RíO (2012), p. 255. El autor pone en relieve que la presunción de inocencia sólo cede ante la sentencia firme y tal firmeza se alcanza una vez fallado, de proceder, el recurso interpuesto en su contra, por lo cual concluye ante tal supuesto que el procedimiento penal se estructura en base a la existencia de recursos.

${ }^{50}$ Así es denominado el antiguo procedimiento penal por cuanto no existía división en las funciones de investigar, acusar y sentenciar otorgando demasiadas atribuciones en los jueces. A modo referencial PFEFFER (2001); RODRÍGUEZ (2013), p. 670.

51 PFEFFER (2001).

52 DEL RÍO (2012), p. 312.

53 BIBLIOTECA DEL CONGRESO NACIONAL (2018), pp. 241, 329, 330, 380 y 522, entre otras, del Primer Trámite Constitucional.
} 
De este modo, se impuso el recurso de nulidad penal, por sobre los de apelación ${ }^{54} \mathrm{y}$ casación hasta entonces vigentes, y en reemplazo de la mencionada opción de un recurso extraordinario ${ }^{55}$. Esta opción se consideró, por lo demás, más coherente con la "concepción acusatoria que ha conducido al legislador a construir un sistema de recursos en que se disminuye la actuación de los tribunales superiores y se da a los recursos este carácter restrictivo" ${ }^{56}$.

\subsection{Configuración del recurso de nulidad penal}

El recurso de nulidad penal puede ser definido como "un recurso extraordinario que se interpone por la parte agraviada por una sentencia definitiva dictada en un procedimiento ordinario, simplificado o de acción privada, ante el tribunal que la dictó, con el objeto de que el superior jerárquico que sea competente, en conformidad a la ley, invalide el juicio oral y la sentencia, o solamente esta última" ${ }^{57}$. Del Río afirma que este recurso tiene como fundamento objetivo el error de forma o fondo, y como fundamento subjetivo la búsqueda de justicia ${ }^{58}$.

Son características que configuran el recurso de nulidad penal las que a continuación se explican.

En primer lugar, procede en contra de determinadas sentencias. En efecto, solo son resoluciones susceptibles de este recurso la sentencia definitiva dictada con ocasión de un juicio oral, de un juicio oral simplificado, las dictadas en procedimientos de acción privada y en el procedimiento de extradición pasiva ${ }^{59}$. Este carácter es coherente con la propuesta sistémica del Código Procesal Penal que establece "un modelo que claramente disminuye la intensidad del régimen de los recursos" ${ }^{60}$, argumento que fue gravitante en el período de discusión para imponerse frente a otros recursos.

La sentencia definitiva debe ser impugnada presentando este recurso por escrito y dentro de los diez días siguientes a aquél en que la sentencia es notificada (artículo 372, inciso segundo). La oportuna interposición del recurso de nulidad suspende los efectos de la sentencia condenatoria recurrida (artículo 379 ). Si, por el contrario, no se deduce oportunamente, la sentencia adquiere el carácter de firme o ejecutoriada ${ }^{61}$. Una vez adquirido ese carácter, produce el efecto de cosas juzgada ${ }^{62}$.

En segundo lugar, este medio de impugnación es de derecho estricto, por cuanto tiene como fundamento de admisibilidad sólo algunos "motivos de nulidad", los que se encuentran taxativa y específicamente consagrados en el Código Procesal Penal. Dichas causales se pueden agrupar en genéricas y concretas ${ }^{63}$.

Las causales genéricas se describen en el artículo 373 del Código Procesal Penal. La primera de ellas consiste en la infracción sustancial de derechos fundamentales durante el procedimiento o sentencia. La segunda, consiste en la errónea aplicación del derecho que influya sustancialmente en la parte dispositiva del fallo. Como se puede apreciar, ambas consisten en vulneración de normas, sean constitucionales o legales.

Las causales concretas se encuentran en el artículo 374 del Código Procesal Penal, bajo la expresión motivos absolutos de nulidad. Se refiere a una multiplicidad de situaciones diversas: a) sentencia dictada por tribunal o jueces no habilitados para el efecto, describiendo detalladamente aquellos casos; b) juicio desarrollado en ausencia de personas cuya presencia

\footnotetext{
${ }^{54}$ DEL RíO (2012), p. 262. El autor recuerda que si bien el recurso de apelación se vuelve improcedente en contra de la sentencia pronunciada en un juicio oral, aún procede sobre algunos aspectos contenidos en ésta, relativo a los beneficios y las costas.

${ }^{55}$ BIBLIOTECA DEL CONGRESO NACIONAL (2018), pp. 410, 423 y 484, entre otras, del Segundo Trámite Constitucional.

${ }^{56}$ CHAIGNEAU (2002), p. 305.

${ }^{57}$ HORVITZ Y LÓPEZ (2010), p. 402.

58 DEL RÍO (2012), pp. 250-254

59 CHAIGNEAU (2002), p. 310.

60 PALOMO Y ALARCÓN (2011), p. 310.

${ }^{61}$ Artículo 174 del Código de Procedimiento Civil chileno, aplicable al ámbito penal en virtud de lo dispuesto por el artículo 52 del Código Procesal Penal.

${ }^{62}$ Artículo 175 del Código de Procedimiento Civil chileno, aplicable al ámbito penal en virtud de lo dispuesto por el artículo 52 del Código Procesal Penal chileno.

63 SILVA (2017), p. 171
} 
continuada se exija; c) cuando al defensor se le haya impedido ejercer facultades; d) si en el juicio fueron violadas las disposiciones sobre publicidad y continuidad; e) sentencia pronunciada con omisión de ciertos requisitos legales; f) sentencia emitida con vulneración al principio de congruencia y; g) sentencia dictada contra otra pasada en autoridad de cosa juzgada.

En tercer término, el recurso de nulidad exige, además, su preparación, entendiéndose por tal la reclamación oportuna del vicio por parte del interviniente ${ }^{64}$. Al respecto, expresa el artículo 477: "Si la infracción invocada como motivo del recurso se refiriere a una ley que regulare el procedimiento, el recurso sólo será admisible cuando quien lo entablare hubiere reclamado oportunamente del vicio o defecto". Si el recurso no fuere preparado, el tribunal ad quem deberá declararlo inadmisible (artículo 483, inciso segundo, del Código Procesal Penal).

Conviene reconocer que el inciso segundo del artículo 477 atenúa el alcance de esta exigencia, al establecer los casos en que no es procedente: "No será necesaria la reclamación del inciso anterior cuando se tratare de alguna de las causales del artículo 374; cuando la ley no admitiere recurso alguno contra la resolución que contuviere el vicio o defecto, cuando éste hubiere tenido lugar en el pronunciamiento mismo de la sentencia que se tratare de anular, ni cuando dicho vicio o defecto hubiere llegado al conocimiento de la parte después de pronunciada la sentencia". En otras palabras, esencialmente procede para las causales del artículo 473.

La exigencia de preparación del recurso permite reforzar la afirmación de Palomo y Alarcón, quienes sostienen que este instrumento ha sido concebido como un medio de impugnación de parte ${ }^{65}$. Esta concepción es una lógica consecuencia del artículo 352 del código del ramo, de la imparcialidad del juez y del principio de contradicción propio del juicio oral.

En cuarto lugar, se trata de un recurso que se interpone ante el mismo Tribunal que dictó la resolución, pero su conocimiento y fallo corresponde al superior jerárquico: la Corte de Apelaciones respectiva o la Corte Suprema, según la causal de nulidad invocada.

En base a lo anterior, es posible afirmar que, por regla general, el conocimiento del recurso de nulidad es competencia de la Corte de Apelaciones respectiva. Eso ocurre cuando se invoca la causal del artículo 373, letra b), o cualquiera de las incluidas en el artículo 374 del Código Procesal Penal. La Corte Suprema sólo es competente en caso de invocarse la causal del artículo 373 letra a) y, excepcionalmente, lo será en la situación contemplada en la letra b) del mismo artículo cuando respecto de la materia objeto del mismo existieren diversos criterios sostenidos en fallos emanados de los tribunales superiores ${ }^{66}$. De ahí que su intervención sea más bien excepcional. De igual modo, conocerá nuestro máximo Tribunal si un recurso se fundare en varias causales y al menos una de ellas sea competencia de la Corte Suprema o; cuando se interpusieren diversos recursos de nulidad contra una misma sentencia y entre las causales hubiese una que sea resorte de la Corte Suprema.

Por último, se establecen los casos en que no resulta procedente deducir el recurso de nulidad penal. Al respecto, textualmente expresa el artículo 387, inciso segundo, del Código Procesal Penal: "Tampoco será susceptible de recurso alguno la sentencia que se dictare en el nuevo juicio que se realizare como consecuencia de la resolución que hubiere acogido el recurso de nulidad. No obstante, si la sentencia fuere condenatoria y la que se hubiere anulado hubiese sido absolutoria, procederá el recurso de nulidad en favor del acusado, conforme a las reglas generales".

La disposición recién transcrita permite distinguir las siguientes situaciones, según explican Mosquera y Maturana: "Si la primera sentencia, esto es, la anulada era absolutoria y la dictada en el segundo juicio también lo es, no procederá el recurso de nulidad en contra de esta. Si la primera sentencia fue absolutoria y la segunda es condenatoria, procede igualmente

${ }^{64}$ SILVA (2017), p. 170.

65 PALOMO Y ALARCÓN (2011), p. 309.

${ }^{66}$ Artículo 376, inciso segundo, del Código Procesal Penal chileno. 
nulidad en contra de esta última. Si la primera fue condenatoria y también lo es la segunda, no procede el recurso de nulidad en contra de esta última" ${ }^{67}$.

A partir de las explicaciones de Maturana y Mosquera, es posible identificar los casos en los que sí procede y los casos en los que no procede el recurso de nulidad penal. El recurso de nulidad solo procede bajo dos supuestos. Primero, siempre procede en contra de la sentencia dictada en el primer juicio, sea esta condenatoria o absolutoria. $Y$, segundo, dicho recurso procede en contra de la dictada en el segundo juicio solo si ésta fue condenatoria y la pronunciada en el primero fuere absolutoria.

Por el contrario, el recurso de nulidad penal se torna irremediablemente improcedente en cuatro casos. Primero, si la primera sentencia fue absolutoria, la segunda condenatoria y la tercera absolutoria o condenatoria. Segundo, si la primera sentencia fue condenatoria y la segunda absolutoria. Tercero, si ambas sentencias fueron absolutorias. Y cuarto, si ambas sentencias fueron condenatorias. Sin duda, esta última hipótesis es la que genera mayores inconvenientes prácticos a la luz de la jurisprudencia de la Corte Interamericana y, tratados suscritos por nuestro país sobre la materia y los razonamientos por parte de nuestra doctrina.

\section{Evaluación del recurso de nulidad penal desde las exigencias del derecho fundamental al recurso}

Este último apartado se trabaja en base a tres ejes. Cada uno de ellos contrasta las exigencias del derecho al recurso (primer apartado de este trabajo) con la configuración que actualmente presenta el recurso de nulidad penal (segundo apartado de este trabajo). De este modo, se aborda la configuración del recurso de nulidad penal a la luz de las exigencias que debiese satisfacer para cumplir el estándar del derecho fundamental al recurso pretendido.

\subsection{El recurso de nulidad frente a la exigencia de que el imputado tenga derecho a un recurso}

El ordenamiento procesal penal cumple de manera imperfecta con la exigencia de poner a disposición del imputado un recurso para impugnar la sentencia.

De un lado, cumple con dicha exigencia al contemplar el recurso de nulidad. Este recurso puede ser deducido por el imputado en contra de la sentencia pronunciada en el respectivo juicio. Sin embargo, este cumplimiento es deficiente por diversas razones.

\subsubsection{Se priva del derecho al recurso al imputado dos veces condenado, aunque no lo haya} ejercido

El imputado no puede recurrir en contra de la sentencia condenatoria pronunciada en un segundo juicio, pese a no haber ejercido este derecho en contra de la sentencia también condenatoria recaída en el primer juicio.

El caso es el siguiente. Un imputado es condenado en el primer juicio y se conforma con la decisión. Sin embargo, el Ministerio Público o el acusador particular no están conformes con algún aspecto de la sentencia condenatoria. Por ello, deducen recurso de nulidad. Si la Corte respectiva acoge dicho recurso, ordenará la realización de un nuevo juicio. En este segundo juicio el imputado podría ser condenado a una pena más gravosa que la aplicada luego del primer juicio.

El supuesto recién descrito puede ser mejor comprendido con un ejemplo. La sentencia recaída en el primer juicio fue condenatoria, pero favorable al imputado por haberse acogido su tesis de defensa. Por ejemplo, si se acreditó el delito de hurto simple ${ }^{68}$ y no de receptación en

67 MOSQUERA Y MATURANA (2012), p. 383.

${ }^{68}$ Código Penal chileno, artículo 446. 
carácter de reiterada ${ }^{69}$. En tal caso podría recurrir quien sostiene la pretensión punitiva, sea el Ministerio Público o el acusador particular. Como consecuencia, la sentencia dictada en el nuevo juicio podría resultar más gravosa para el imputado, que la impuesta en la sentencia pronunciada en el primer juicio.

El artículo 387, inciso segundo, no permite deducir el recurso de nulidad en contra de la sentencia condenatoria pronunciada en el segundo juicio, si la recaída en el primero también fue condenatoria. Esta disposición es razonable si el imputado ejerció su derecho al recurso en contra de la primera sentencia. Por el contrario, priva del derecho fundamental a un recurso para impugnar la sentencia al imputado que nunca recurrió por haber estado conforme con el fallo dictado con motivo del primer juicio, como se ejemplificó en el párrafo anterior. Por tanto, se trata de una regulación que vulnera el derecho fundamental al recurso ${ }^{70}$.

Pese a lo recién argumentado, el Tribunal Constitucional chileno se ha pronunciado en sentido contrario. En la causa rol $986-2007^{71}$ rechazó un requerimiento de inaplicabilidad por inconstitucionalidad respecto del inciso segundo del artículo 387 del Código Procesal Penal. El argumento del recurrente de inaplicabilidad fue precisamente el sostenido en estas líneas. Sin embargo, el máximo intérprete de la Constitución sostuvo "que el condenado se colocó en este caso en la posición de no haber podido recurrir de nulidad por no haber impugnado la sentencia dictada en el primer juicio y que, además, existiría la posibilidad de recurrir de queja en contra de ese fallo"72.

Lo preocupante no es sólo el escenario aquí descrito que torna ilusorio la posibilidad de interponer el recurso a fin de gozar y ejercer el derecho al recurso, sino que actualmente nuestro país se encuentra evaluando una serie de aportes para el perfeccionamiento reforma procesal penal $^{73}, y$, dentro de éstos, no se hace mención a esta deficiencia advertida.

\subsubsection{El recurso deducido por el imputado puede conducir a una pena más gravosa}

La vulneración a la exigencia de un recurso para que el imputado pueda impugnar la sentencia no solo se vulnera porque se le priva de ejercer este derecho, aunque nunca haya recurrido. Dicha exigencia también puede resultar vulnerada si el imputado ejerce su derecho al recurso.

Puede ocurrir que el imputado recurra contra la sentencia condenatoria dictada en el primer juicio. En tal caso se realizará un segundo juicio. La sentencia recaída en este último podría ser igualmente condenatoria. Esto no parece objetable. El problema se produce si esta segunda sentencia condena al imputado a una pena más gravosa. Una tal posibilidad no está vedada por el ordenamiento procesal penal chileno. Y su verificación no parece coherente con la exigencia de otorgar al imputado un recurso para impugnar la sentencia ${ }^{74}$.

Fue precisamente el supuesto recién descrito el que condujo a un imputado a presentar un recurso de inaplicabilidad ante el Tribunal Constitucional chileno. Sin embargo, el máximo intérprete de la Constitución lo rechazó, mediante sentencia del año 2007 en causa rol 1130-

\footnotetext{
${ }^{69}$ Código Penal chileno, Artículo 456 Bis A, inciso 4․

${ }^{70}$ Corte de Apelaciones de Temuco, Rol № 894-2015, de 25 de agosto de 2015. En el caso hubo un primer juicio oral, en el que se acogió la tesis de la defensa y se condenó al amparado y a su coimputado como autores de robo en lugar no habitado. El imputado fue condenado a la pena de 200 días de presidio menor en su grado mínimo. Se alzó contra dicho fallo el Ministerio Público que había acusado por robo en lugar habitado, obteniendo la nulidad del juicio y la sentencia por haberse aplicado erróneamente normas sobre determinación de la pena sólo respecto del amparado. En el segundo juicio oral, a este último se le condenó por delito de robo en lugar habitado, a una pena de 8 años de privación de libertad.

${ }^{71}$ Tribunal Constitucional chileno, Rol № 986-2007, de 30 de enero de 2008. Se recurrió de inaplicabilidad por inconstitucional respecto de la resolución dictada en el segundo juicio que no dio lugar al recurso de nulidad. En el primer juicio el imputado fue condenado por homicidio simple. A su respecto, recurrió el ente persecutor de nulidad no haciéndolo el imputado, y tras la realización del segundo juicio, el imputado fue condenado por el delito de homicidio calificado con el agravante de alevosía.

72 MOSQUERA Y MATURANA (2012), p. 384.

${ }^{73}$ MINISTERIO DE JUSTICIA (2019).

${ }^{74}$ No nos pronunciamos respecto de la reformatio in peius en la sentencia recaída en el recurso, por cuanto la competencia funcional de la Corte está delimitada por las peticiones incluidas en el recurso deducido por el imputado.
} 
$2007^{75}$. El caso se había originado porque se dedujo un recurso de nulidad en contra de la sentencia recaída en el segundo juicio, también condenatoria y más gravosa para el imputado. Sin embargo, el tribunal rechazó conceder el recurso de nulidad porque el recurrente había sido condenado en las dos sentencias. Y en tal escenario, el ordenamiento jurídico impide acoger a tramitación un recurso de nulidad que conduzca a un tercer juicio.

Este defecto en la configuración del recurso de nulidad ha sido advertido por la doctrina. Es por ello que en la Comisión Ministerial que trabaja en la elaboración de modificaciones al Código Procesal Penal se ha sostenido la idea de "asegurar al acusado que el ejercicio del derecho a recurrir contra la sentencia condenatoria, en los casos de anulación de juicio, no puede tener un efecto aún más perjudicial que la sentencia que emana del juicio anulado (artículo 387). En ese sentido, se pretendió consagrar la prohibición de reforma peyorativa en relación al acusado recurrente, pues de lo contrario el derecho al recurso del condenado, consagrado en los tratados internacionales sobre derechos humanos, no podría hacerse efectivo" ${ }^{\prime 6}$.

\subsubsection{El recurso de nulidad se niega al imputado en situaciones de vulneración de derechos}

La configuración del recurso de nulidad penal no parece satisfacer la exigencia de otorgar al imputado un recurso para impugnar la sentencia condenatoria, porque en ciertos casos se le priva del mismo, aunque exista vulneración de derechos humanos.

Aquello ocurre cuando el imputado recurra de la primera sentencia condenatoria. Si se acoge su recurso, podría imponerse la celebración de un nuevo juicio. Pues bien, podría ocurrir que en el segundo juicio se presenten vicios que constituyan vulneración de derechos humanos del imputado. Y que, como consecuencia de aquello, se dicta una nueva sentencia condenatoria.

De acuerdo con la configuración del recurso, es improcedente recurrir de nulidad en contra de la segunda sentencia condenatoria. Incluso en un escenario tan grave como es la contravención de derechos humanos. Un cierre de este carácter no parece consistente con la exigencia de otorgar al imputado un recurso para impugnar la sentencia. Frente a esta constatación, resultan singularmente acertadas las ideas de Palomo y Alarcón, cuando expresan que, "por una parte, se reconoce el derecho al recurso y, por otra, se le limita o minimiza con el fin de mantener y tutelar la centralidad de lo que genera el juicio oral" 77 .

\subsubsection{El recurso se otorga en perjuicio del imputado}

El recurso de nulidad puede ser deducido tanto por el imputado, como por cualquiera de los demás intervinientes en el juicio oral. De este modo, el recurso también se otorga en perjuicio del primero. Esta posibilidad no parece ajustarse a la exigencia de otorgar al imputado un recurso para impugnar la sentencia, por dos razones.

En primer lugar es, a lo menos, discutible permitir al Ministerio Público, como órgano del Estado, hablar de vulneración de garantías del debido proceso. Los derechos fundamentales, y entre ellos el derecho al recurso, tienen por finalidad proteger a las personas, los subordinados o justiciables, frente a la actividad punitiva de los estados.

En segundo término, parece extraño que un imputado deba sostener judicialmente su inocencia sobre un mismo hecho en dos oportunidades. Una tal posibilidad debería permitirse de mera excepcional, y no bajo las simples causales del recurso de nulidad ${ }^{78}$.

\footnotetext{
75 Tribunal Constitucional chileno, Rol № 1130-2007, de 07 de octubre de 2008.

${ }^{76}$ ZALIASNIK et al. (2019), p. 17.

77 PALOMO Y ALARCÓN (2011), p. 311.

78 DEL RíO (2012), p. 264. El autor plantea que, si bien es discutible, no parece escandalosa la discusión teniendo en consideración la simpleza extrema del legislador en lo que respecta a la configuración de las causales.
} 


\subsection{El recurso de nulidad frente a la exigencia de que se trate de un recurso ordinario, eficaz y sencillo}

El recurso de nulidad parece cumplir parcialmente los estándares del derecho fundamental al recurso, en lo relativo a la exigencia de tratarse de un mecanismo ordinario, eficaz y sencillo.

\subsubsection{El recurso de nulidad frente a la exigencia de un recurso ordinario}

El recurso de nulidad es un recurso extraordinario desde el punto de vista de la clasificación procesal: procede solo contra determinadas sentencias. Sin embargo, es un recurso ordinario en el sentido que la Corte IDH le da a esta expresión. En efecto, y según se indicó más arriba, la Corte entiende que un recurso es ordinario si permite su interposición con anterioridad a que la sentencia provoque el efecto de cosa juzgada. El recurso de nulidad cumple con esta exigencia.

\subsubsection{El recurso de nulidad frente a la exigencia de un recurso eficaz}

El recurso de nulidad es un recurso parcialmente eficaz.

El recurso de nulidad penal es conocido por un tribunal superior respecto de aquel que dictó la sentencia impugnada. En efecto, por regla general, el recurso debe ser conocido por la Corte de Apelaciones respectiva. Incluso bajo ciertos supuestos, ya analizados, es conocido por la Corte Suprema. Por tanto, se cumpliría este primer requisito incluido en la exigencia de tratarse de un recurso eficaz por permitir su corrección ante un tribunal superior.

Sin embargo, no ocurre lo mismo con la exigencia de permitir la corrección de decisiones contrarias a Derecho. Manifestación de esta afirmación es que el recurso de nulidad no permite anular parcialmente el juicio, vale decir, sólo aquellos hitos o actuaciones con vicios manteniendo las que no lo presentaron. Solo permite anular la totalidad del juicio. Como se dijo, su finalidad es anular el juicio y la sentencia o sólo esta última. Distinguir esto es relevante, por cuanto hay múltiples escenarios en torno a un juicio oral: atribuirle varios hechos a un mismo imputado, un hecho a un sólo imputado, o varios delitos a diversos imputados. La nulidad de uno de los hechos o respecto de ciertas personas, puede no necesariamente ser pretendida por los otros y, pese a ello, alcanzarles.

Por lo anterior, y como afirma Duce, establecer de forma expresa la nulidad parcial ayudaría a "consolidar aquella porción del juicio que no ha tenido vicios de ninguna especie o no ha sido objeto de reclamación alguna" 79 . La pertinencia de una tal propuesta se confirma con el siguiente antecedente: se encuentra en actual estudio la incorporación de la nulidad parcial, tal como existe hoy en la ley procesal laboral ${ }^{80}$. Sin duda, la institución de la nulidad parcial ayudaría a salvar esta deficiencia haciendo más armónico y coherente el texto de nuestro CPP con la finalidad perseguida al momento de la configuración del recurso en comento, evitar vicios, vale decir, mantener porciones o actuaciones conformes a derecho.

\subsubsection{El recurso de nulidad frente a la exigencia de un recurso sencillo}

El recurso de nulidad no es un recurso sencillo. Esto se debe, por una parte, a que para su admisibilidad el interesado debe acreditar la "preparación del recurso". Esto significa, según ya se expresó, que la parte debió reclamar del vicio en cuanto se produjo o tomó conocimiento del mismo, si se trata de las causales de nulidad establecidas en el artículo 473 del Código Procesal Penal. Tavolari afirma que esto resulta contradictorio si justamente una de las consideraciones

79 DUCE (2015).

${ }^{80}$ ZALIASNIK et al. (2019), p. 16. 
que se tuvo en cuenta para eliminar los recursos de casación fue su extrema formalidad. En efecto, durante la discusión parlamentaria se sostuvo que "con este nuevo tratamiento del recurso se pretende simplificar la institución" 81 , lo que por cierto no ha ocurrido.

En idéntico sentido, el profesor Palomo advierte que la intención sostenida al momento de la discusión y configuración del recurso de nulidad, de establecerlo como un recurso sin mayores rigores formales como los propios de la casación, no prosperó, identificando que ello obedece al excesivo formalismo y rigurosidad de la institución en su configuración ${ }^{82}$ lo que pugna con la finalidad que la misma persigue, lo cual pareciera reflejar que la aplicación del referido mecanismos para atacar la sentencia penal se aleja de su espíritu.

\subsection{El recurso de nulidad frente a la exigencia de permitir una revisión integral del fallo impugnado}

Por revisión íntegra se "debe otorgar competencia suficiente al Tribunal ad quem para revisar íntegramente la decisión" ${ }^{83}$. El recurso de nulidad no parece cumplir los estándares del derecho fundamental al recurso en lo relativo a la exigencia de permitir la revisión integral de la sentencia impugnada. En efecto, por la configuración del recurso, la competencia del tribunal superior queda reducida a los motivos expresamente previstos en la ley ${ }^{84}$. Y esos motivos 0 causales de procedencia del recurso solo permiten impugnar dos aspectos de la sentencia: los de carácter probatorio y los de carácter jurídico impidiendo la revisión de los hechos.

Como se advierte, hay una situación no cubierta: la revisión de los hechos. Esta posibilidad se contempló en el desechado recurso extraordinario. Según se explicó, dicho recurso procedía si la sentencia condenatoria pronunciada en un juicio oral se hubiere apartado manifiesta y arbitrariamente de la prueba rendida. Pues bien, con la configuración de nuestro recurso se impide tal revisión y alcance, siendo génesis de ello la discusión de aquel entonces sobre la materia por cuanto se consideró que, aún sin la revisión de los hechos, igualmente se satisfacía la garantía constitucional de acceso al recurso ${ }^{85}$.

En tal sentido, parece posible sostener que no cumple con la exigencia de permitir la revisión integral de la sentencia impugnada lo cual implica. De ahí que con acierto exprese Tavolari la siguiente idea: "En el derecho de los recursos tenemos algo que resolver porque aceptamos sin mayor debate: a) Recursos que no permiten la revisión de los hechos" ${ }^{\prime 86}$. Esto, sin duda, obedece a la estricta rigurosidad en su confección como a la preeminencia de las instituciones y principios rectores de la reforma procesal penal, en donde la inmediación y oralidad parecieran imponerse a la finalidad primitiva perseguida: un mecanismo especializado y que sirva de solución a los problemas de rigurosidad de la casación.

Impedir la revisión de los hechos tiene un enorme impacto en la decisión del caso. El diseño del recurso de nulidad penal olvida esta cuestión esencial: sin hechos no hay aplicación del Derecho. En este sentido, con acierto expresa la Corte Interamericana que en la actividad jurisdiccional una errónea determinación de los hechos implica una errada o indebida aplicación del derecho ${ }^{87}$.

Lo anterior no ha sido abordado por la Comisión Asesora para la nueva reforma Procesal Penal, pese a la normativa internacional, a la responsabilidad internacional del estado chileno determinadas por sentencias de la Corte IDH y al aporte que gran parte de nuestra especializada

\footnotetext{
81 Opinión del profesor Raúl Tavolari en Primer Informe de Comisión de Constitución, en sesión 17, Legislatura 338, de fecha 04 de agosto de 1998. BIBLIOTECA DEL CONGRESO NACIONAL (2018), p. 629.

82 PALOMO (2010), p. 495. El autor trabaja esta y otras ideas recogiendo importantes aportes de doctrina sobre el recurso de nulidad, advirtiendo esta y otras deficiencias del mismo a modo de prevenir para que ello acontezca en el símil de la Reforma Procesal Civil.

${ }^{83}$ LETELIER (2014), p. 153. El autor realiza una clara precisión de lo que comprende la revisión íntegra de la sentencia recurrida. Por un lado, sostiene, que el Ad Quem debe poder revisar la decisión, sus motivaciones y el alcance de ésta y; por otro, los hechos.

${ }^{84}$ PALOMO Y ALARCÓN (2011), p. 310; DEL RíO (2012), p. 260.

85 PALOMO (2010), p. 498

86 TAVOLARI (2013), p. 45.

${ }^{87}$ Norín Catrimán y Otros vs. Chile (2014), Corte Interamericana de Derechos Humanos. Párrafo 270, letra d).
} 
doctrina han efectuado respecto de éste y otros inconvenientes relacionados con la configuración del recurso de nulidad penal.

\section{Comentarios finales y conclusión}

El derecho al recurso es un derecho procesal que forma parte del conjunto de otros que integran el derecho humano al debido proceso, el cual se forja como una limitación a los poderes de los estados y se tiene por el sólo hecho de ser persona, exista o no reconocimiento constitucional o regulación legal interna de éste.

Al estudiar el contenido del catálogo de derechos de nuestra carta fundamental con detención, a la luz de los tratados internacionales suscritos y ratificados por Chile y vigentes, sobre todo en base a los criterios de la Corte IDH y lo consagrado en la CADH, éste resulta poco feliz. No garantiza plenamente el ejercicio y goce del derecho al debido proceso, ya que no asegura ni eleva a tal categoría el derecho al recurso, considerado como un mínimo a nivel internacional. Por su parte, la regulación del Código Procesal Penal chileno sobre el recurso de nulidad penal es deficiente por alejarse del estándar de sencillez y eficacia y, además, por no preverlo en ciertos escenarios.

Dentro de estas deficiencias se destacan, en primer lugar, que el código del ramo cuenta con un elevado estándar de exigencia para su interposición y fundamentación lo que se desprende de sus causales taxativas y en la rigurosidad del examen de admisibilidad, a diferencia de la sencillez y el fácil acceso pretendido y consagrado a nivel interamericano conforme los instrumentos internacionales sobre la materia.

Un segundo inconveniente que presenta la regulación de nuestro actual código procesal penal, en atención al recurso de nulidad, es que no contempla la figura de la nulidad parcial, por lo cual la finalidad perseguida con la declaración de nulidad se distorsiona ya que también se anularía aquella parte del juicio que no presentó vicios lo cual atenta, precisamente, con una de las finalidades máximas del recurso de nulidad, la cual es salvar aquella porción del juicio que no los presentó.

Un tercer problema advertido es que no permite al tribunal superior revisar los hechos lo que, si bien se adapta a una de las ideas base de la reforma procesal penal de mantener como piedra angular de la misma la oralidad del juicio, esta configuración se enfrenta al postulado de la Corte IDH de que el imputado tendrá derecho a que un tribunal superior proceda a revisar tanto los hechos como el derecho.

Una cuarta deficiencia que atenta no sólo al derecho al recurso sino que, también, a otras garantías fundamentales y recogidas en criterios de la Corte Interamericana y normativa internacional, es la prohibición de su interposición en situaciones de vulneración de garantías fundamentales con motivo del segundo juicio en el escenario que la sentencia dictada tras este segundo juicio sea condenatoria y aquella dictada en el primero igualmente lo haya sido.

Siguiendo esta ilación, un quinto problema que presenta su actual configuración es que sólo permite su interposición frente a tres situaciones o, dicho de otro modo, excluye la posibilidad de su interposición en cuatro escenarios, tornando imposible que el imputado condenado en un primer juicio, quien no ejerció su derecho al recurso por serle favorable la condena en base a su teoría del caso y quien, frente al segundo juicio forzado por el ente persecutor resulta nuevamente condenado, sea o no a una pena más gravosa, pueda ejercer su derecho al recurso. Esto, por cierto, atenta al postulado de que toda persona declarada culpable por un delito siempre tendrá derecho a la revisión íntegra del fallo.

Ante esto, los criterios emanados por la Corte Interamericana de Derechos Humanos, la normativa internacional, teniendo presente el mandato de incorporación de éstos por Convencionalidad, enriquecen y permitirían salvar, en parte, las deficiencias advertidas. Sin embargo, nuestro país no cuenta con la fuerza vinculante del precedente a fin de generar certeza jurídica para que los criterios consagrados en los fallos citados y la normativa internacional se impongan plenamente, sin necesidad de que el imputado deba impetrar nuevas acciones 
judiciales, en casos de silencio de nuestro legislador o contradicción de nuestra normativa interna frente a lo asentado a nivel interamericano. Con todo, el sólo hecho de intentar suplir estas deficiencias advertidas mediante el Control de Convencionalidad dan luces de que a la configuración actual del recurso de nulidad dentro del código procesal penal no basta en sí misma.

A raíz de lo expuesto, y pese a los intentos que realiza nuestro país virtud de los proyectos de reforma, tanto constitucional -en lo que respecta al derecho al debido proceso, como legal reforma a la reforma procesal penal, nuestra configuración del recurso de nulidad penal es deficiente e inadecuada conforme a lo consagrado en materia de derechos humanos reconocido en diversos instrumentos internacionales, principalmente la CADH y los criterios de la Corte IDH recogidos en diversos fallos sobre la materia.

\section{BIBLIOGRAFÍA CITADA}

Alexy, Robert (2001): Teoría de los derechos fundamentales (Traducc. Ernesto Garzón, Madrid, Centro de Estudios Políticos y Constitucionales).

BECA, JUAN (2014): "El uso de tratados internacionales por parte del Tribunal Constitucional al resolver recursos de inaplicabilidad en el período 2011-2012", en: Revista de Derecho de la Pontificia Universidad Católica de Valparaíso (Vol. 43, № 2), pp. 467-493. Disponible en: https://scielo.conicyt.cl/pdf/rdpucv/n43/a12.pdf [visitado el 30 de mayo de 2019].

Biblioteca del Congreso Nacional (1974): "Actas Oficiales de la Comisión Constituyente, Segunda Parte de la Sesión $N^{\circ} 83$ de fecha 31 de octubre de 1974". Disponible en: https://www.bcn.cl/lc/cpolitica/constitucion_politica/Actas_comision_ortuzar/Tomo_III_Comisio n_Ortuzar.pdf [visitado el 02 de julio de 2018].

Biblioteca del ConCejo NaCiOnal (2018): "Historia de la Ley 19.696". Disponible en: https://www.bcn.cl/historiadelaley/fileadmin/file_ley/6631/HLD_6631_37a6259cc0c1dae299a78 66489dffobd.pdf [visitado el 13 de julio de 2020].

BORDALÍ, ANDRÉS (2011): "Análisis crítico a la jurisprudencia del Tribunal Constitucional sobre el derecho a la tutela judicial", en: Revista Chilena de Derecho (Vol. 38, № 2), pp. 311-337. Disponible en: https://scielo.conicyt.cl/pdf/rchilder/v38n2/art06.pdf [visitado el 28 de abril de 2019].

BORDALí, ANDRÉS (2013): "La independencia de los Jueces en la aplicación de la Ley dentro de la organización judicial chilena", en: Revista Chilena de Derecho (Vol. 40, № 2), pp. 609-634. Disponible en: https://scielo.conicyt.cl/pdf/rchilder/v40n2/art10.pdf [visitado el 06 de noviembre de 2020].

Cámara de Diputados (2017): "Proyecto de Ley que: "Modifica la Carta Fundamental para perfeccionar la regulación contenida en los capítulos I a VIII en las materias que indica". Boletín $\mathrm{N}^{\circ} 11.342-2017 "$.

Disponible

en: https://www.camara.cl/legislacion/ProyectosDeLey/tramitacion.aspx?prmID=11855\&prmBoletin $=11342-07$ [visitado el 13 de julio de 2020].

Chaigneau, Alberto (2002): "Sentencia y recursos en el nuevo sistema Procesal Penal", en: Revista Chilena de Derecho (Vol. 29, № 2), pp. 303-313. Disponible en: https://dialnet.unirioja.es/servlet/articulo?codigo=2650266 [visitado el 15 de julio de 2020].

Comité de Derechos humanos de Naciones Unidas (2000): "Dictamen del Comité de Derechos Humanos emitido al tenor del párrafo 4 del artículo 50 del Protocolo Facultativo del Pacto Internacional de Derechos Civiles y Políticos". Disponible en: http://hrlibrary.umn.edu/hrcommittee/spanish/701-1996.html [visitado el 13 de mayo de 2019].

Corte Interamericana De Derechos Humanos (2017): "Cuadernillo de Jurisprudencia de la Corte Interamericana de Derechos Humanos. № 12. Debido Proceso". Disponible en: 
http://www.corteidh.or.cr/sitios/libros/todos/docs/cuadernillo12.pdf [visitado el 12 de julio de 2020].

Del Río, CARLOS (2010): "Tres apuntes sobre el recurso de nulidad y el enjuiciamiento fáctico a propósito de tres fallos de la ilustrísima Corte de Apelaciones de La Serena", en: Revista de Derecho de la Universidad Católica del Norte (Año 17, № 1), pp. 131-146. Disponible en: https://scielo.conicyt.cl/pdf/rducn/v17n1/art06.pdf [visitado el 15 de mayo de 2018].

Del Río, CARlos (2012): "Estudio sobre el derecho al recurso en el proceso penal", en: Revista Estudios Constitucionales (Año 10, № 1), pp. 245-288. Disponible en: https://scielo.conicyt.cl/pdf/estconst/v10n1/art07.pdf [visitado el 30 de junio de 2018].

DUCE, MAURICIO (2015): “Nulidades parciales: Llegó la hora de asentar una jurisprudencia razonable". Disponible en: http://www.elmercurio.com/legal/movil/detalle.aspx?ld=903634\&Path=/0D/C9/ [visitado el 13 de mayo de 2019].

GALDÁMEZ, LILIANA (2014): “El valor asignado por la jurisprudencia del Tribunal Constitucional a la jurisprudencia de la Corte Interamericana de Derechos Humanos", en: Revista Estudios Constitucionales (Año 12, № 1), pp. 329-364. Disponible en: https://scielo.conicyt.cl/pdf/estconst/v12n1/art08.pdf [visitado el 06 de noviembre de 2020].

GARCÍA, GoNZALO y CONTRERAS, PABLO (2013): "El derecho a la tutela judicial y al debido proceso en la jurisprudencia del Tribunal Constitucional chileno", en: Revista Estudios Constitucionales (Año 11, № 2), pp. 229-282. Disponible en: https://scielo.conicyt.cl/pdf/estconst/v11n2/art07.pdf [visitado el 25 de junio de 2018].

HenRíQuez, Miriam (2018): “Cimientos, auge y progresivo desuso del control de convencionalidad interno: veinte interrogantes", en: Revista Chilena de Derecho (Vol. 45, № 2), pp. 337-361. Disponible en: https://scielo.conicyt.cl/pdf/rchilder/v45n2/0718-3437-rchilder-45-02-00337.pdf [visitado el 23 de abril de 2019].

Henríquez, MiRIAm (2019): "La naturaleza del Control Interno de Convencionalidad y su disímil recepción en la jurisprudencia de las normas chilenas", en: Revista Derecho del Estado, Universidad Externado de Colombia (№ 43, mayo-agosto), pp. 131-157. Disponible en: http://www.scielo.org.co/pdf/rdes/n43/0122-9893-rdes-43-131.pdf [visitado el 09 de noviembre de 2020].

HITTERS, JUAN (2009): “Control de Constitucionalidad y Control de Convencionalidad. Comparación”, en: Revista Estudios Constitucionales (Año 7, № 2), pp. 109-128. Disponible en: https://scielo.conicyt.cl/pdf/estconst/v7n2/art05.pdf [visitado el 05 de julio de 2018].

HITTERS, JUAN (2015): “Control de convencionalidad (adelantos y retrocesos)", en: Revista Estudios Constitucionales (Año 13, № 1), pp. 123-162. Disponible en: https://scielo.conicyt.cl/pdf/estconst/v13n1/art05.pdf [visitado el 23 de abril de 2019].

HORVITZ, MARÍA Y LÓPEZ, JULIÁN (2010): Derecho procesal penal chileno (Santiago de Chile, Editorial jurídica de Chile), tomo II.

LETELIER, ENRIQUe (2014): “El Derecho Fundamental al Recurso según la doctrina jurisprudencial del sistema interamericano de protección de los derechos humanos", en: Revista Europea de Derechos Fundamentales (primer semestre, № 23), pp. 141-160. Disponible en: https://dialnet.unirioja.es/servlet/articulo?codigo $=4945875$ [visitado el 02 de noviembre de 2020].

MINISTERIO DE JUSTICIA (2019): "Ministerio de Justicia y DD.HH. recibe informe de la Comisión Asesora para la Reforma Procesal Penal". Disponible en: https://www.minjusticia.gob.cl/ministro-dejusticia-y-dd-hh-recibe-informe-de-la-comision-asesora-para-la-reforma-procesal-penal/ [visitado el 21 de mayo de 2019]. 
MOSQUERA, MARIO Y MATURANA, CRISTIAN (2012): Los recursos procesales, 2a edición (Santiago de Chile, Editorial Jurídica de Chile).

NASH, CLAUDIO (2013): “Control de convencionalidad. Precisiones conceptuales y desafíos a la luz de la jurisprudencia de la Corte Interamericana de Derechos Humanos", en: Anuario de Derecho Constitucional Latinoamericano (Año 19), pp. 489-509. Disponible en: http://www.corteidh.or.cr/tablas/r32199.pdf [visitado el 21 de abril de 2019].

NogueIRA, HUMBerTo (2008): Derechos fundamentales y garantías constitucionales (Santiago de Chile, Editorial Librotecnia), volumen II.

Olano, HeRnÁn (2016): "Teoría del Control de Convencionalidad", en: Revista Estudios Constitucionales (Año 14, № 1) pp. 61-94. Disponible en: https://scielo.conicyt.cl/pdf/estconst/v14n1/art03.pdf [visitado el 04 de julio de 2018].

PALOMO, DiEGo (2010): “Apelación, doble instancias y proceso civil oral. A propósito de la reforma civil en trámite", en: Revista Estudios Constitucionales (Año 8, № 2), pp. 465-524. Disponible en https://scielo.conicyt.cl/scielo.php?script=sci_arttext\&pid=S0718-52002010000200014 [visitado el 08 de noviembre de 2020].

PALOMO, DIEGO Y ALARCÓN, HUMBERTO (2011): “Fundamentación de la sentencia y contradicción, como materialización del derecho al recurso en materia procesal penal", en: Revista lus et Praxis (Año 17, № 1), pp. 291-320. Disponible en: https://scielo.conicyt.cl/pdf/iusetp/v17n1/art15.pdf [visitado el 18 de mayo de 2019].

PfEFFER, EMILIO (2001): “Entrada en vigencia del nuevo código procesal penal en el país", en: Revista lus et Praxis (Vol. 7, № 2), pp. 259-271. Disponible en: https://scielo.conicyt.cl/scielo.php?script=sci_arttext\&pid=S0718-00122001000200011 [visitado el 05 de noviembre de 2020].

RodRíGUez, MANUEl (2013): "Sistema acusatorio de justicia penal y principio de obligatoriedad de la acción penal", en: Revista de Derecho de la Pontificia Universidad Católica de Valparaíso (№ 40), pp. 643-686. Disponible en: https://scielo.conicyt.cl/pdf/rdpucv/n40/a20.pdf [visitado el 05 de noviembre de 2020].

SILVA, RodRIGo (2017): Manual de procedimiento penal, 3a edición (Santiago de Chile, Editorial Jurídica de Chile).

TAVOLARI, RAÚl (2013): "Mayor respeto entre jueces y abogados", en: Seminario Reformas a la reforma procesal penal, Academia Parlamentaria. Disponible en: http://www.academiaparlamentaria.cl/Archivo.aspx?idArchivo=248 [visitado el 12 de mayo de 2019].

Zaliasnik, Gabriel; Correa, Carlos; Duce, Mauricio; De la Barra, Rodrigo; Espinoza, Alejandro;

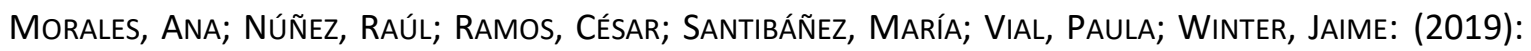
"Informe de la Comisión Asesora Ministerial para el perfeccionamiento del Código Procesal Penal", en:

http://www.minjusticia.gob.cl/media/2019/01/INFORME_DE_LA_COMISION_ASESORA_MINISTE RIAL_PARA_EL_CPP.pdf [visitado el 21 de mayo de 2019].

\section{JURISPRUDENCIA CITADA}

NACIONAL

AARÓN DAVID VÁSQUEZ MUÑOZ (2008): Tribunal Constitucional 30 de enero de 2008 (Inaplicabilidad por Inconstitucionalidad), Rol № 986-2007, en: https://app.vlex.com/\#vid/58941825. 
CAROLINA GAJARDo SANDOVAL (2008): Tribunal Constitucional 07 de octubre de 2008 (Inaplicabilidad por Inconstitucionalidad), Rol № 1130-2007, en: https://app.vlex.com/\#vid/58941465.

MATÍAS MUNDACA CAMPOS Y FRANCISCO CATALDO ARAYA (2010): Tribunal Constitucional 26 de agosto de 2010 (Inaplicabilidad por Inconstitucionalidad), Rol № 1443-2010, en: https://app.vlex.com/\#vid/219113942.

JONATHAN GONZÁlez gARcíA (2015): Corte de Apelaciones de Temuco 25 de agosto de 2015 (Acción de Amparo), Rol № 894-2015, en: https://app.vlex.com/\#search/jurisdiction:CL/8942015+corte+apelaciones+temuco/WW/vid/581212898.

NeL GREeVEN BOBadilla (2017): Tribunal Constitucional 20 de abril de 2017 (Inaplicabilidad por Inconstitucionalidad), Rol № 3119-2016, en: https://www.tribunalconstitucional.cl/ver2.php?id=3432.

VEREDICTO AD 1386-2014 (2014): Corte Suprema 16 de mayo de 2019 (Procedimiento Especial de colaboración en el cumplimiento de la sentencia dictada por la Corte Interamericana de Derechos Humanos el 29 de mayo de 2014), Rol AD-1386-2914, en: http://decs.pjud.cl/corte-supremadeclara-que-las-sentencias-condenatorias-dictadas-en-caso-norin-catriman-y-otros-vs-chile-hanperdido-todos-los-efectos-que-les-son-propios/.

\section{INTERNACIONAL}

MYRNA MACK CHANG CON GUATEMALA (2003): Corte Interamericana de Derechos Humanos, de fecha 25 de noviembre de 2003, Fondo, Reparaciones y Costas. Disponible en: http://www.corteidh.or.cr/docs/casos/articulos/seriec_101_esp.pdf.

HERRERA ULLOA CON COSTA RICA (2004): Corte Interamericana de Derechos Humanos, de fecha 02 de julio de 2004, Excepciones Preliminares, Fondo, Reparaciones y Costas. Disponible en: http://www.corteidh.or.cr/docs/casos/articulos/seriec_107_esp.pdf.

ALMONACID ARELLANO Y OTROS CON CHILE (2006): Corte Interamericana de Derechos Humanos, de fecha 26 de septiembre de 2006, Excepciones Preliminares, Fondo, Reparaciones y Costas. Disponible en: http://www.corteidh.or.cr/docs/casos/articulos/seriec_154_esp.pdf.

MOHAMED VS. ARGENTINA (2012): Corte Interamericana de Derechos Humanos, de fecha 23 de noviembre de 2012, Excepción Preliminar, Fondo, Reparaciones y Costas. Disponible en: http://www.corteidh.or.cr/docs/casos/articulos/seriec_255_esp.pdf.

NORÍN CATRIMÁN Y OTROS CON CHILE (2014): Corte Interamericana de Derechos Humanos, de fecha 29 de mayo de 2014, Fondo, Reparaciones y Costas. Disponible en: http://www.corteidh.or.cr/docs/casos/articulos/seriec_279_esp.pdf.

AMRHEIN Y OTROS VS. COSTA RICA (2018), Corte Interamericana de Derechos Humanos, de fecha 25 de abril de 2018, Excepciones Preliminares, Fondo, Reparaciones y Costas. Disponible en: https://www.corteidh.or.cr/docs/casos/articulos/seriec_405_esp.pdf.

RUIZ FUENTES Y OTRA VS. GUATEMALA (2019), Corte Interamericana de Derechos Humanos, de fecha 10 de octubre de 2019, Excepción Preliminar, Fondo, Reparaciones y Costas. Disponible en: https://www.corteidh.or.cr/docs/casos/articulos/seriec_384_esp.pdf.

\section{NORMAS JURÍDICAS CITADAS}

CÓDIGO DE PROCEDIMIENTO CIVIL CHILENO.

CóDIGO PENAL CHILENO.

CÓDIGO PROCESAL PENAL CHILENO. 
CONSTITUCIÓN POLÍTICA DE LA REPÚBLICA DE CHILE.

CONVENCIÓN AMERICANA SOBRE DERECHOS HUMANOS. 1969.

CONVENCIÓN DE VIENA SOBRE EL DERECHO DE LOS TRATADOS. 1969.

DECLARACIÓN AMERICANA DE DERECHOS Y DEBERES DEL HOMBRE. 1948.

LEY № 19.519, crea el Ministerio Público. Diario Oficial, 16 de septiembre de 1997.

LEY 19.640, establece Ley Orgánica Constitucional del Ministerio Público. Diario Oficial, 15 de octubre de 1999.

LEY 19.718, crea la Defensoría Penal Pública. Diario Oficial, 10 de marzo de 2001.

LEY 20.886, modifica el Código de Procedimiento Civil, para establecer la tramitación digital de los procedimientos judiciales. Diario Oficial, 18 de diciembre de 2015.

PACTO INTERNACIONAL DE DERECHOS CIVILES Y POLÍTICOS. 1966. 